\title{
Some Analytical Consideration on Indonesian Metal Music
}

\section{Gianluca Cellini}

\begin{abstract}
The widespread of metal music had crossed the borders of its native lands as a musical and socio-cultural phenomenon that emerged many studies mostly starting from sociological standpoint. By emphasizing the musicological aspect, this paper tried to show how the theoretical proposals of some scholars may be reflected in particular metal music through structural analysis approach. The analysis of a particular folk metal music in Indonesia showed the inclination of its instruments to mimic the interlocking of Balinese Gamelan in terms of patterns, hierarchy, and scale. The character of folk metal music in Indonesia was explained as the rebellion against a world unrestrained consumerism yet in the same time was an attempt to follow the post-modern need to find meeting points that is practicable. This paper suggested to insert the phenomenon of Indonesian metal music in the broader framework of worldwide expansion of this genre.
\end{abstract}

Keywords: metal music, folk metal, structural analysis, transnational

Metal music is since many years a musical genre that has crossed the borders of its native lands to spread globally as a musical and socio-cultural phenomenon of this phase of capitalist modernity. There are a lot of studies, much of whom starting from a sociological standpoint, that focus on this huge transnational expansion of the genre, placing it in relation to its own cultural dynamics of globalization ongoing process. I will return to these studies in the conclusions, trying to show how the theoretical proposals of some scholars may be reflected in what I will analyze in short. For now I just propose some statistics to show how the global spread of the metal is a reality that cannot be overshadowed.

First of all we observe that in International Encyclopedia of Hard Rock and Heavy Metal (Jasper et al. 1983), only 15 of the 1.500 listed band were born outside from Europe, America and Australia; in 2011 the online Encyclopedia Metallum contained 47,626 band from 129 countries (Wallach, Berger \& Green 2011). The recent research by Jeremy Wallach and Esther Clinton on google trends show that countries with more research for the terms Heavy Metal Music Genre are, in order: Indonesia, Chile, El Salvador, Costa Rica. The ranking for the terms Trash Metal is: Chile, Paraguay, Costa Rica, Colombia. We find again in first place Indonesia for the search of Death Metal, immediately followed by 
Chile, Costa Rica and El Salvador (Clinton \& Wallach 2015). These simple statistics, without any pretension of being exhaustive, put quite clearly to light that the geography of metal music is today reshape, bringing almost in balance the relationship between the West and the Rest.

The Indonesian situation fits into this general context. The country has a huge metal scene: in the important site aforementioned metal-archives.com, 1,167 bands are well reported to have originated from the archipelago (www.metalrchives.com/list/ID consulted on $23 / 09 / 2015$. Note that some of the band marked are reported as "split up". It is anyway likely that the band no longer existing are still fewer the those who have never been added to the site.), and for example, in the city of Yogyakarta, considered by many a little "metalheads" city, you can listen to a live metal at least once a week.

Ascertained therefore the size of the expansion of the metal, I would now be more specific about some strictly musicological issues, because it seems necessary today to try to fill the gap between the sociological and the more closely musicological work on the topic: I am convinced that only a careful analytic work on the sound data can help increase our understanding how and why millions of people around the world feel the need to express themselves through Metal Music.

Of particular interest for the research that I am conducting are those bands that fit into the trend of so-called folk metal, one of the many sub-genres that are part of the heavy metal galaxy, characterized by the more or less explicit recovery of sounds, instruments and melodies from traditional music. Born in northern Europe in the 90's, it is experiencing today a major globally expansion, and new current seem to grow steadily. In Indonesia there are not many bands that refer to their genre as Folk Metal. The scene is still quite small and perhaps immature, but there are nevertheless interesting cases. Pioneers of the genre in the country were the Balinese Eternal Madness, formed in 1994 in Denpasar, that define their genre as 'Lunatic Ethnic Black Metal'. Their way of composing was analyzed by Jeremy Wallach in his important book Modern Noise: Fluid Genres (Wallach 2005 and Wallach 2008) fundamental book about popular music in Indonesia. Already in this volume the American scholar highlighted as some special metrical-rhythmical particularity of some song of Eternal Madness were due to the fact that the assemblages of the melodic lines of the various instruments were designed to mimic the interlocking of Balinese Gamelan. It's the Eternal Madness's instrumental piece Trance Elixir, from 2007 cd Abad Kegilaan that I start to consider analytically. The song begins with a bass guitar solo performing a melody in eighth note that we could write as follows: 


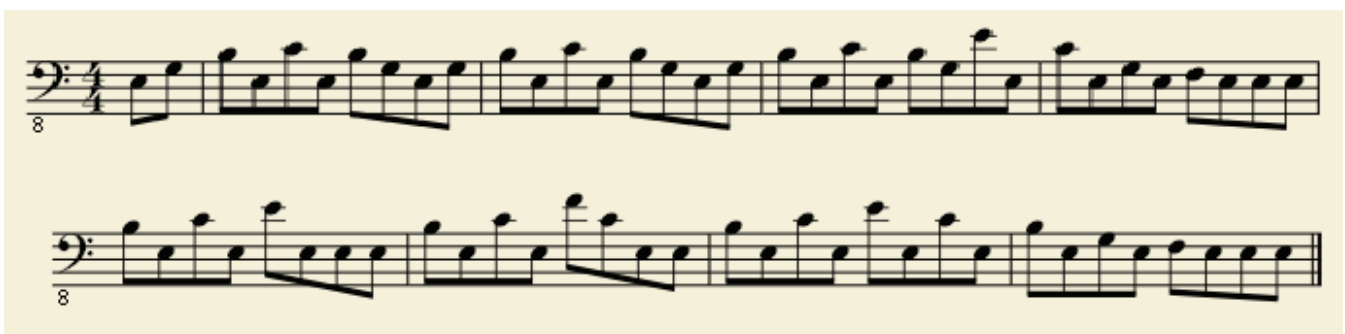

Image 1: Introduction of Trance Elixir

It is a structure formed by different phrases, each of which of 4 beats; this pattern is then repeated throughout the introduction with the gradual incoming of the other instruments that determinate the increasing of sound strength. Although the previous transcription can actually be exhaustive, thinking all in the more usual 4/4 of metal music, just having a little knowledge of Indonesian traditional music is enough to understand that perhaps things are not exactly like that.

Let's try for example to consider the first two eighth note not like the first time of a 4/4 beat, but rather as the first gong of a traditional composition, and to write, rather than with the Western notation, with the numerical notation in use for gamelan (the sound used are, as we have seen, E, F, G, B, C. In the numeric trancriprion they became 1, 2, 3, 5, 6 . The 1 and 2 in bold indicate the note at higher octave):

$\begin{array}{llllllll}35 & 16 & 15 & 31 & 35 & 16 & 15 & 3(1) \\ 35 & 16 & 15 & 11 & 16 & 13 & 12 & 1(1) \\ 15 & 16 & 11 & 11 & 15 & 16 & 12 & 6(1) \\ 15 & 16 & 11 & 13 & 15 & 13 & 12 & 1(1)\end{array}$

What results, therefore, it is a structure formed by three 8 times rhytmic cycle, with the second repeated after the third. To confirm the feeling such organization there is the occurrence, starting from the second cycle, of a particularly evident event in correspondence with what, in a traditional composition, it would be the gong ageng: more specifically, for the first four times, it is the intervention of the ride of the drum set that make a triplet, to which are added in the fourth repetition keyboards and in the fifth the chords of the guitar and so on, creating a big growth of the sound.

There are other aspect that may be taken in consideration in this few second of introduction, such as the use of effects for the bass guitar that modify the envelope of the sound, making it in some way similar to that of percussion instruments with central bulb, 
but I believe that the particular metrical sense of the song is more interesting because, in a direct way, it connects with the second song that I would consider.

This is the song Tirta Kedustaan from the album Menuju KeagunganMu by Beauty of Blood, band coming from Sidoarjo, Surabaya. This group seems to be particularly interesting because, stated that its wish is to combine metal music with the traditional music of Indonesia, they uses in the line-up two saron. This links them to many European folk metal band, but it is a situation that, to my current state of knowledge, is unique in the metal scene of the Indonesian archipelago. Once again we are faced with an instrumental introduction where the main instrument is precisely the saron.

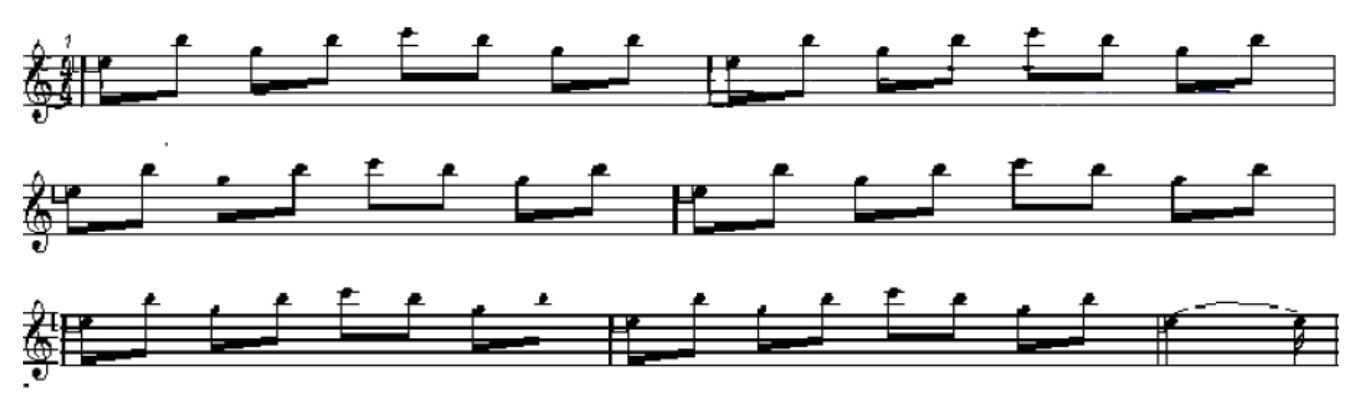

Image 2: Introduction of Tirta Kedustaan

Once again we can see that this part of the song could be easily understand as the six-times repetition of a eight note $4 / 4$ bar but, even in this case, everything seems to work better if we consider the first $\mathrm{E}$ as the first gong ageng, and we face with the same situation found above:

\section{$\begin{array}{llllllll}5 & 3 & 5 & 1 & 5 & 3 & 5 & (1)\end{array}$}

Also in this case the song assumes a different form, becoming an eight-times rhythmic cycle, in which the function of the gong ageng is assumed by guitar, bass guitar and drums, which mark the right end of each rhythmic cycle. In the same song we find a rhythmic ambiguity even in in the section immediately following. Here, western and Indonesian metrical organization seem to be used together. On one hand the drum play the most common 4/4 metal backbeat, and that does not contradict the accentuation pattern of the sarn which, while respecting their traditional performance practice, seems to play without giving much relevance to any beat.

Completing these two sections mainly instrumental, where a grow/voice appared only occasionally, there's a long section sung by the clean female voice. The aspects that I think 
is necessary to consider are at least two, because they help us to understand the way of thinking and acting of the musical group in question and, more widely, of the metal Indonesia band.

Fist of all I want to notice technique used by the singer. Unfortunately the recording quality and the presence of all the instruments playing at the intervention of the singer make it almost impossible an accurate analysis of the spectrum. However, taking in consideration the second $1: 34$, in which the singer stops on a single note, we can derive the spectrogram shown in Figure 3.

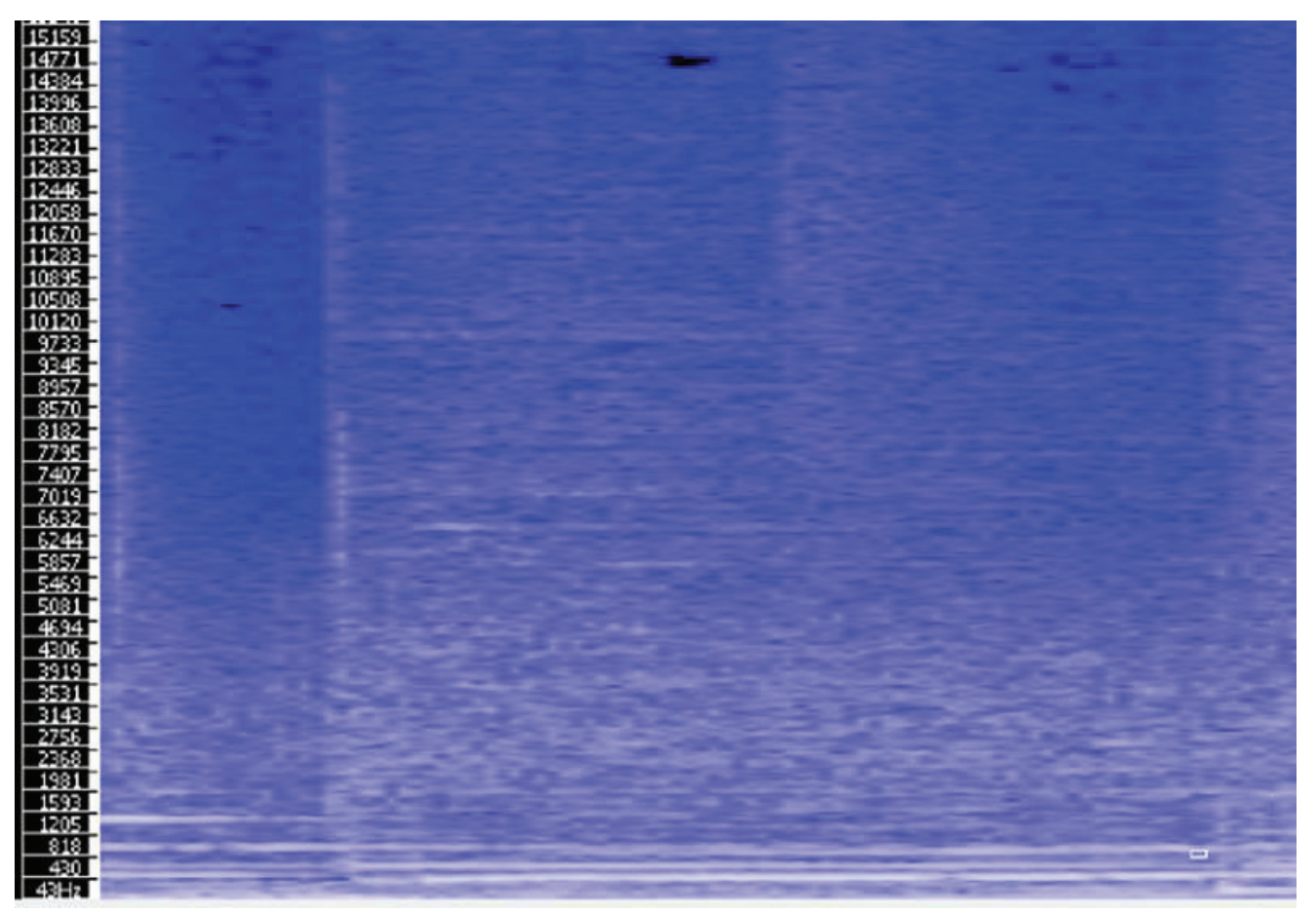

Image 3: spectrum of second 1,34 of Tirta Kedustaan

As we can see, it takes a considerable reinforcement of the formants located approximately in the range between 7000 and $1400 \mathrm{hz}$, which means, as it is possible to perceive also listening, a certain nasalization of sound. Obviously the sound position within the mask is not comparable to the vocal technique of Sindhenan, but not even close to the lyrical one used by most female singers of the European metal scene. It seems to me that, once again, the technique and the traditional sounds attempt in this piece of the Beauty of Blood to adapt and blend with a completely different stile (the issue of vocal techniques use in metal seems to be very important fot the understanding of the genre.

On one side there are analytical and classifiers studies; Mesïa \& Ribaldini 2015; on the other scholar tries to investigate how the the extremes vocal techniques, as well as other aspects of timbre, is usefull to create an overall "affective overdrive"; Wallach, Berger \& 
Green 2011; for the symbolic value that vocal timbre can have, the mediation operated by Beauty of Blood seems to be particular interesting).

The second, emerging from the analysis of the female vocal in Tirta Kedustan, is related to scale systems in use in Indonesian folk metal. The case seems particularly proper, but we could find similar situations in other pieces (i.e. in the song Doxa, by the band Fadhalius from Yogyakarta). Listening to the voice it seems pretty clear that something is wrong between this and the instruments, which play a diatonic accompaniment (note that, like shown in image 2 , the saron are diatonically tuned to match with the western instruments), enough to make it appear that the singer is jarring. But measuring the fundamental frequencies (thus trying as much as possible to remove the ornamentation), we can trace a sequence of six intervals whose difference in $\mathrm{Hz}$ is the following one:

\begin{tabular}{|l|l|l|l|l|l|l|l|l|l|l|l|l|l|}
\hline Note & La & & Si & & Do & & Re & & Mi & & Fa & & Sol \\
\hline $\begin{array}{l}\text { Hz } \\
\text { Balance }\end{array}$ & & 43,1 & & 21,5 & & 64,6 & & 86,2 & & 75,3 & & 43,1 & \\
\hline Interval & & $\mathrm{S}$ & & $\mathrm{S}$ & & $\mathrm{S} ?$ & & $\mathrm{~L}$ & & $\mathrm{~L}$ & & $\mathrm{~S}$ & \\
\hline
\end{tabular}

Once again we are facing with an ambiguous use of the musical elements, in this case the height of the notes, and the resulting scalar system. As we see from the table above, only two of the intervals in the model are the same, while among the other passes differences rather obvious. So, rather than thinking at the use of a minor scale, I suggest that the underlying logic of the organization is which of big and small interval of the traditional Pelog scale.

In the previous pages I tried to frame some musical elements from two songs that I consider interesting and representative of the Indonesian folk metal scene, trying in this way to open up the field to a few broader conclusions that, however, will require further study that will pass necessarily from the ethnomusicological tenets, such as field work and the multi- musicality: only these steps will confirm or refute the hypothesis that, now, I'm going to expose.

The phenomenon of metal in Indonesia should be inserted in the broader framework of the worldwide expansion of the genre; the most significant attempt to understand this phenomenon in the context of the cultural dynamics of globalization has been done in the volume Metal Rules the Globe: Heary Metal around the World (Wallach, Berger \& Green, 2011), where it is shown that the construction of a transnational ideal community of enthusiasts and practitioners is a possible way to respond to those that the authors consider the two major challenges of globalization: the questioning of traditional values for the ever more frequent contact with other realities, and the rapid and often 
violent change of entire cities and regions caused by the worldwide capitalistic expansion. Becoming part of the metal scene, in the thought of the authors, is a way to refuse both the most common answers to these upheavals that are on one hand the subjection to the consumer society, and on the other the total rejection of change and the self-segregation in a world sharply divided between "us and them". The above examples seem in a fair measure to go to confirm the truth of this hypothesis, since, on the one hand, the rebellion against a world unrestrained consumerism is expressed by the sound elements of its genre (distorted guitars, growl voice etc.), while on the other the attempt to harmonize two traditions strongly distant seems to follow the post-modern (or post-postmodern?) need to find meeting points that are not only compromises, but third practicable ways. In the globalized and transcultural world, even the form of expression have became transcultural: the Indonesian folk metal seems to be a good example of this crossbred way of thinking and acting and, therefore, a good test for those who want to confront with making music in the XXI century.

\section{REFERENCES}

Berger, H., M. 1997. The Practice of Perception: Multi-Functionality and Time in the Musical Experiences of a Heavy Metal Drummer, in Ethnomusicology 41 (n³) pp. 464488, University of Illinois Press.

Barone, S. 2015. Metal Identities in Tunisia: Locality, Islam, Revolution, Modern Heavy Metal: Markets, Practices and Cultures. Edited by Karjalainen, T-M e Karki, K. Available as an on line E-Book at http://iipcblog.wordpress.com/publications/

Clinton, E, Wallach, J. 2005. Recoloring the metal map: metal and race in global prospective, in Modern Heavy Metal: Markets, Practices and Cultures. Edited by Karjalainen, T-M e Karki, K. Available as an on line E-Book at http://iipcblog.wordpress.com/publications/

Ferrarese, M. 2015. Heavy Metal nothingness: alluring foreignness and authenticity construction in early 2010s Malaysian metal, in Modern Heavy Metal: Markets, Practices and Cultures. Edited by Karjalainen, T-M e Karki, K. Available as an on line E-Book at http://iipcblog.wordpress.com/publications/

Mesiä, S, Ribaldini, P. 2015. Heavy Metal Vocals: a terminology compendium, Modern Heavy Metal: Markets, Practices and Cultures. Edited by Karjalainen, T-M and Karki, K. Available as an on line E-Book at http:/ /iipcblog.wordpress.com/publications/

Wallach, J. 2005. Engineering Techno-Hybrid Grooves in Two Indonesian Sound Studios, in Green, P. D. e Porcello, T. (a cura di), Wired for Sound: Engineering and Technologies in Sonic Culture. Wesleyan University Press, Middletown, pp. 138-155.

Wallach, J. 2008. Modern noise, fluid genres: popular music in Indonesia 1997-2001. University of Wisconsin Press. Madison.

Wallach, J, Berger, M, H, Green, P, D. 2011. Metal rules the globe: metal music around the world. Duke University Press. Durham.

Weinstein, D. 2000. Heavy Metal: The music and its culture. New York. Da Capo. 
IJCAS: Vol. 4, No. 1 June 2017

\section{Sitography}

www.beautyofbloodsidoarjo.blogspot.com

www.eternalmadnessbali.blogspot.co.id

www.metal-archives.com

www.modernheavymetal.net 